\title{
Pneumonia: how important are local epidemiology and smoking habits?
}

\author{
F. Blasi, S. Aliberti
}

Monaldi Arch Chest Dis 2006; 65: 1, 3-4.

Keywords: Community acquired pneumonia, epidemiology, smoking, hospital acquired pneumonia, oxidative stress.

Institute of Respiratory Diseases, University of Milan, Ospedale Maggiore IRCCS Fondazione Policlinico Milano, Italy.

Correspondence: Francesco Blasi, MD; Istituto di Tisiologia e Malattie dell'Apparato Respiratorio, University of Milan; Fondazione IRCCS Ospedale Maggiore Policlinico, Mangiagalli e Regina Elena; Padiglione L. Sacco; e-mail: francesco.blasi@ unimi.it

In this issue of Monaldi Archives, Al-Muhairi et al. describe the epidemiology of Communityand Hospital-acquired pneumonia in United Arab Emirates over five years [1].

Most of the cases $(287,80 \%)$ were actually community-acquired (CAP) and only 74 hospital acquired (HAP). Considering the five-year observation only a few HAP cases each year were observed and no clear conclusion can be drawn from this series.

More interesting are the observations that the annual admission rate for CAP increased from 250/100,000 admissions in 1997 to $710 / 100,000$ in 2002 and the presence of a seasonal trend in the admission rate.

The lack of any established rules for hospital admission can only partially explain the increase in the number of patients hospitalised. A change in population risk factors or in CAP etiology can also be involved but, unfortunately, these variables are not addressed by this study.

For example, in Al-Muhairi study, as commonly reported in the majority of studies into pneumonia, there is a large proportion of cases that have no pathogen identified, mainly because the appropriate tests were not performed [2]. In this study less than $30 \%$ of patients had sputum examination, less than $50 \%$ blood culture and only $14 / 287$ had serology tests. This is a major pitfall of the study, that cannot give any indication on CAP etiology in the examined aerea.

The seasonal differences in CAP incidence seem to be clearly related to population migration. This is an interesting point, rarely addressed in literature. The authors suggest that the peak of pneumonia cases follows the return from Asia of the expatriate population, this means a transmission of infections from Asian residents to local population. What is not clear is that only $3 \%$ of admitted patients are Asians. This may imply a high rate of infection spreading between Asian immigrants and the local population, underlying the importance of etiologic studies in this setting. Both increasing incidence and seasonal variation should foster the authors to design a new study to better investigate the epidemiological risk factors and the etiology of $\mathrm{CAP}$ in their population.
Another interesting article in this issue of Monaldi Archives addresses the effect of cigarette smoking on hydrogen peroxide $\left(\mathrm{H}_{2} \mathrm{O}_{2}\right)$ and thiobarbituric reactive substances (TBARs) concentrations in exhaled breath condensate (EBC) in patients with CAP [3].

The effects of tobacco smoke on the airway mucosa are well known. The chronic inhalation of smoke favours the adhesion of S. pneumoniae and $H$. influenzae to the buccal epithelium. Smoking alters mucociliary transport, humoral and cellular defences, and epithelial cells. The proportion of smokers in hospitalised pneumonias is generally increased, which would indicate a role of smoking in the acquisition of infection.

In the Stolarek et al. study the different responses to oxidative stress in smokers and nonsmokers with CAP is addressed. The study relies on the use of EBC, an interesting non-invasive technique for obtaining samples from the lungs. In EBC large number of mediators including hydrogen peroxide, isoprostanes, leukotrienes, nitrogen oxides, peptides and cytokines can be detected. Data from literature shows that concentrations of these mediators are influenced by lung diseases and modulated by therapeutic interventions.

As recently stated in the ATS/ERS recommendations on EBC [4] $\mathrm{H}_{2} \mathrm{O}_{2}$ concentrations increase during bronchopulmonary infections and decrease after antibiotic treatment in cystic fibrosis patients [5].

However, day to day intra-subject coefficient of variation of $43 \%$ in healthy subjects has been reported [6].

The effects of smoking on EBC mediators concentration is well known; smoking has considerable effect on $\mathrm{H}_{2} \mathrm{O}_{2}$, isoprostane, nitrite and nitrotyrosine levels [7-9].

In Stolarek et al. [3] study the $\mathrm{H}_{2} \mathrm{O}_{2}$ time-related concentrations detected in $\mathrm{EBC}$ result lower in smokers than in non-smokers, whereas TBARs levels increase more in smokers than in non-smokers. These surprising results are probably related, as stated by the authors, to an impaired host response to infection related to a smoking-sustained airways chronic inflammation. 
Clearly more studies are needed to ascertain the pathogenetic role of these findings and the possible need for different treatment approaches to smokers with pneumonia.

In conclusion, this issue of Monaldi Archives addresses two important problems.

As stated by all guidelines local epidemiology knowledge is of primary importance for correct management of lower respiratory tract infections and the article analysed [1] is a good example of the problems that are faced when obtaining valid epidemiologic data. However risk factor identification is clearly mandatory for improving treatment of pneumonia patients. Smoking effects on oxidative response is one of the potentially important targets concerning new approaches to the management of acute and chronic airway inflammation. Stolarek et al. [3] study results give us more questions than answers, indicating the need for a better understanding of the pathophysiology of airway response to infections.

\section{References}

1. Al-Muhairi S, Zoubeidi T, Ellis M, Gary Nicholls M, Safa W, Joseph J. Demographics and Microbiological Profile of Pneumonia in United Arab Emirates. Monaldi Arch Chest Dis 2006; 65: 13-18.
2. Woodhead M, Blasi F, Ewig S, et al. Guidelines for the management of adult lower respiratory tract infections. Eur Respir J 2005; 26: 1138-80.

3. Stolarek RA, Kasielski M, Rysz J, Bialasiewicz P, Nowak D. Differential effect of cigarette smoking on hydrogen peroxide and thiobarbituric acid reactive substances exhaled in patients with community acquired pneumonia. Monaldi Arch Chest Dis 2006; 65: 19-25.

4. Horvàth I, Hunt J, Barnes PJ. Exhaled breath condensate: methodological recommendations and unresolved questions. Eur Respir J 2005; 26: 523-548.

5. Jobsis Q, Raatgeep HC, Schellekens SL, Kroesbergen A, Hop WC, de Jongste JC. Hydrogen peroxide and nitric oxide in exhaled air of children with cystic fibrosis during antibiotic treatment. Eur Respir J 2000; 16: 95-100.

6. Jobsis Q, Raatgeep HC, Schellekens SL, Hop WC, Hermans PW, de Jongste JC. Hydrogen peroxide in exhaled air of healthy children: reference values. Eur Respir $J$ 1998; 12: 483-485.

7. Van Beurden WCJ, Dekhuijzen PNR, Harff GA, Smeenk FWJM. Variability of exhaled hydrogen peroxide in stable COPD and matched healthy controls. Respiration 2002; 69: 211-216.

8. Guatura SB, Martinez JA, Santos Bueno PC, Santos ML. Increased exhalation of hydrogen peroxide in healthy subjects following cigarette consumption. Sao Paulo Med J 2000; 118: 93-98.

9. Nowak D, Kalucka S, Bialasiewicz P, Krol M. Exhalation of $\mathrm{H}_{2} \mathrm{O}_{2}$ and thiobarbituric acid reactive substances (TBARs) by healthy subjects. Free Radic Biol Med 2001; 30: 178-186.

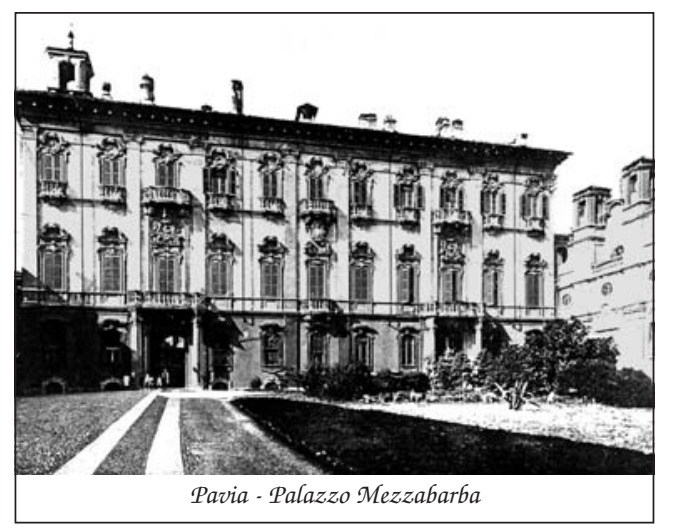

